\title{
The yeast transcription activator PRTF, a homolog of the mammalian serum response factor, is encoded by the MCM1 gene
}

\author{
Eric E. Jarvis, ${ }^{1}$ Karen L. Clark, and George F. Sprague, Jr. ${ }^{2}$ \\ Institute of Molecular Biology and Department of Biology, University of Oregon, Eugene, Oregon 97403 USA
}

Two proteins, $\alpha 1$ and pheromone/receptor transcription factor (PRTF), bind cooperatively to the upstream activation sequences (UAS) of yeast $\alpha$-specific genes and thereby activate their transcription. In these proteinDNA complexes, the PRTF moiety interacts with a degenerate dyad symmetric sequence, the P box. PRTF contributes also to the regulation of a second set of cell-type-specific genes, the a-specific genes. We used two in vitro assays to show that PRTF is encoded, at least in part, by the MCM1 gene. In one assay, truncated MCM1 proteins encoded by deletion derivatives of the MCM1 gene formed protein-DNA complexes of novel mobility, demonstrated that MCM1 can bind to the P-box-containing DNA. Second, antibodies raised to a synthetic MCM1 polypeptide retard the migration of PRTF-DNA complexes in gel mobility shift assays. This result indicates that PRTF, defined as an activity that binds cooperatively with $\alpha 1$ to $\alpha$-specific UAS elements, shares an epitope with MCM1. In addition, we show that MCM1 deletions that remove the carboxy-terminal 129 codons of 286 total codons encode truncated MCM1 molecules that are competent to activate transcription in vivo, indicating that the carboxy-terminal residues are not required for this process.

[Key Words: Yeast; MCM1; PRTF/GRM; cell-type-specific genes; serum response factor]

Received February 28, 1989; revised version accepted April 27, 1989.

Haploid cells of the yeast Saccharomyces cerevisiae exhibit either of two distinct cellular phenotypes, a or $\alpha$. These cell types are specialized for mating and display their unique phenotypes due to the differential expression of two sets of genes: the $\alpha$-specific gene set is transcribed only in $\alpha$ cells, and the a-specific gene set is transcribed only in a cells. These distinct patterns of gene expression are the consequence of the action of two regulatory proteins, $\alpha 1$ and $\alpha 2$, encoded by the $\alpha$ matingtype locus $(M A T \alpha)$. The $\alpha 1$ protein activates transcription of $\alpha$-specific genes, and $\alpha 2$ represses transcription of a-specific genes, so only the $\alpha$-specific gene set is expressed in $\alpha$ cells. Conversely, a cells express only the a-specific gene set because they lack both regulatory proteins (for review, see Sprague et al. 1983; Nasmyth and Shore 1987; Herskowitz 1988).

Insight as to how $\alpha 1$ activates transcription of $\alpha$-specific genes has come from an analysis both of the upstream activation sequences (UAS elements) of $\alpha$-specific genes (UAS; Inokuchi et al. 1987; Jarvis et al. 1988; Flessel et al. 1989) and of the proteins that bind to those UAS elements (Bender and Sprague 1987; Tan et al. $1988)$. These studies revealed that $\alpha 1$ binds at $\alpha$-specific

1Present address: Solar Energy Research Institute, Golden, Colorado 80401 USA.

${ }^{2}$ Corresonding author.
UAS elements cooperatively with a second protein, a transcription factor, pheromone/receptor transcription factor (PRTF), which is present in both $\alpha$ and a cells (and also in $\mathbf{a} / \alpha$ cells produced by mating). The binding site for PRTF is a symmetric dyad, the P box. At $\alpha$-specific genes, however, the sequence is degenerate. It is thought cooperative interaction with $\alpha 1$ is required to compensate for the degenerate nature of the $\mathrm{P}$ sequence, either by simply assisting binding or by inducing an active conformation in PRTF. In either case, binding of $\alpha 1-$ PRTF to the UAS activates transcription.

PRTF also is thought to have roles in the expression of a-specific genes. The binding site for PRTF, the P box, is present within the $\alpha 2$ operator site of these genes (Johnson and Herskowitz 1985). PRTF can bind unaided to the $\mathrm{P}$ boxes of a-specific genes (Bender and Sprague 1987; Tan et al. 1988) and consequently contributes to their transcription activation (Kronstad et al. 1987). PRTF likely has a second, unexpected role in regulation of a-specific genes, namely to act in conjunction with $\alpha 2$ to repress their transcription in $\alpha$ cells. This view is derived from the work of Keleher et al. (1988). They defined a protein, general regulator of mating type (GRM), that could bind alone to the P-box component of an $\alpha 2$ operator and that also could bind cooperatively with $\alpha 2$ to the operator. The ability of the operator to confer repression in vivo required that the binding sites for both 
$\alpha 2$ and GRM be intact. Because both PRTF and GRM bind to $P$ boxes, it seems probable that they are the same protein species. Indeed, in this paper we show that PRTF is encoded, at least in part, by the MCM1 gene, and C.A. Keleher and A.D. Johnson (pers. comm.) have reached the same conclusion for GRM. Thus, combinatorial association of PRTF/GRM with different regulatory proteins, $\alpha 1$ or $\alpha 2$, generates complexes with distinct biological activities.

PRTF has been defined solely on the basis of its DNAbinding properties, and the number of distinct protein species that constitute PRTF is not known. In an effort to identify the structural gene (or genes) for PRTF, we considered whether mutations in any previously identified gene conferred a phenotype consistent with that expected for a cell harboring mutant PRTF molecules. The simple expectation for a PRTF mutant cell would be a failure to express $\alpha$ - and a-specific genes, leading to a nonmating phenotype. However, if PRTF were required for expression of essential genes as well as for $\alpha$ - and a-specific genes-a reasonable possibility given that PRTF is found in a $/ \alpha$ cells - then complete loss of PRTF function would be lethal. Therefore, viable mutant alleles should be defective for only some PRTF activities. For example, such alleles could encode a form of PRTF unable to interact with $\alpha 1$ but still able to bind to symmetric P boxes. In this case, transcription of $\alpha$-specific genes would be depressed, but transcription of other genes would be largely unaffected. The properties of MCM1 mutant strains fit these expectations. The mcm1-1 allele was isolated as a mutation that affected maintenance of certain minichromosomes (Maine et al. 1984). Subsequently, it was observed that mcm1-1 caused a mating defect, but only in $\alpha$ cells, and that transcription of $\alpha$-specific, but not a-specific, genes was depressed severely. Moreover, deletion of MCM1 was lethal (Passmore et al. 1988). Therefore, MCM1 is a candidate for the PRTF structural gene. We report both in vitro and in vivo experiments that provide support for this relationship.

\section{Results}

\section{Truncated MCM1 proteins bind to P(PAL)}

As noted in the introductory paragraphs, PRTF is a biochemical activity defined on the basis of its DNAbinding properties. It is present in extracts of all three cell types and can bind unassisted to the dyad symmetric form of the $\mathrm{P}$ box, $\mathrm{P}(\mathrm{PAL})$ (Bender and Sprague 1987; Jarvis et al. 1988). To investigate whether MCM1 encodes PRTF, first we asked whether MCM1 protein is capable of binding to $\mathrm{P}(\mathrm{PAL})$ by using truncated MCM1 proteins. The formation of complexes of mutant MCM1 molecules with $\mathrm{P}(\mathrm{PAL})$ should be revealed as proteinDNA complexes of novel mobility in electrophoresis mobility shift experiments (bandshifts). To test this expectation, we used three mutations of MCM1 that vary in the number of codons deleted from the carboxyl terminus; one deletion retains codons 1-187 [of 286 total codons, referred to as MCM1 (1-187)], the second retains codons $1-157$, and the third retains codons 1-91.

Bandshift assays were performed using crude extracts prepared from yeast strains wild type at the MCM1 chromosomal locus and also carrying either the multicopy plasmid YEp24 or one of the three deletions cloned into YEp24 (Fig. 1; for details concerning the plasmids, see Fig. 8). Thus, the extracts containing mutant MCM1 molecules also contains wild-type MCM1. Figure 1 (lane 2) shows the mobility of the PRTF-P(PAL) complex formed by extracts of wild-type cells harboring the vector YEp24. The major and uppermost band represents the PRTF-P(PAL) complex; the two minor bands apparently represent nonspecific complexes formed with other proteins in the extract, as they are not competed with excess unlabeled P(PAL) DNA (data not shown) and they do not react with antibodies to MCM1 (see below). The extract containing MCM1 (1-91) formed only the complex characteristic of wild-type extracts, implying that MCM1 (1-91) does not bind to P(PAL) (lane 5). We cannot verify that the MCM1 (1-91) protein was present in the extract, however, because it does not contain the epitope to which MCM1 antibodies were raised (see below). In contrast, extracts containing MCM1 (1-187) or MCM1 (1-157) formed specific complexes with P(PAL) DNA that had distinctly greater mobility than the specific complex formed on $\mathrm{P}(\mathrm{PAL})$ by wild-type extracts (lanes 3 and 4). The particular pattern of complexes is complicated and presumably reflects the formation of heteromeric binding species that included both wild-type and mutant MCM1, a possibility discussed in detail below.

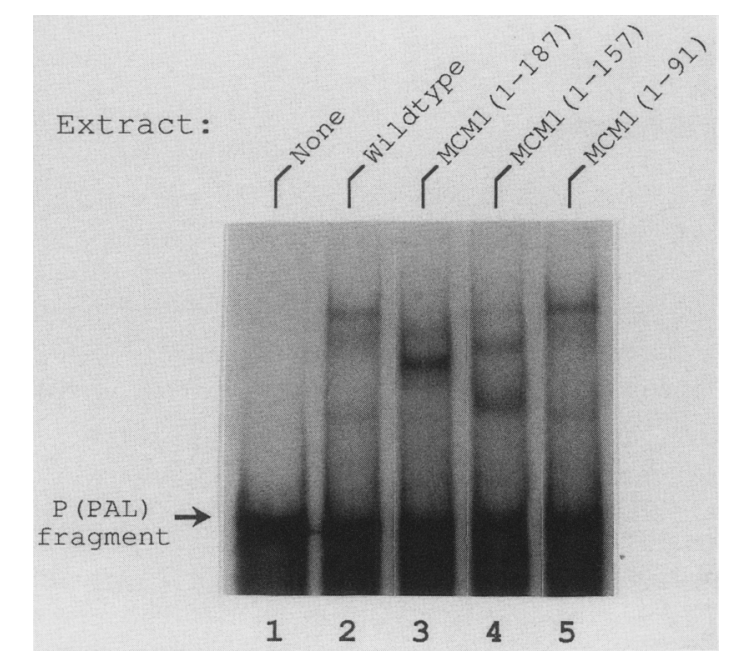

Figure 1. Changes in the MCM1 molecular weight change the mobility of the P(PAL) bound complex. Electrophoresis mobility-shift assays were performed on the 160-bp P(PAL)-containing DNA fragment as described (see Materials and methods). Lane 1 contains no extract. Reactions of lanes 2-5 used extracts from strains bearing the following plasmids: YEp24 (lane 2); MSE24 [MCM1 (1-187)] (lane 3); MSB24 [MCM1 (1-157)] (lane 4); MSS24 [MCM1 (1-91)] (lane 5). Note the differences between lanes 2,3 , and 4 , indicating that a change in the molecular weight of MCMl affects the mobility of the complex directly. 
Two features of the complexes formed by extracts containing MCM1 (1-187) or MCM1 (1-157) are worth noting. First, extracts that contained MCM1 molecules of different molecular weights formed complexes of different mobility. This indicates that MCM1 can bind to $\mathrm{P}(\mathrm{PAL})$. Second, complexes with two (or more) distinct mobilities were seen for each mutant extract, and the wild-type PRTF-P(PAL) complex was present only in very low amounts. Given the conclusion of this paper that MCM1 and PRTF are the same protein species, these observations are consistent with the idea that MCMl binds as a dimer, a possibility suggested by the dyad nature of the $\mathrm{P}(\mathrm{PAL})$ sequences. Thus, we suggest that for each mutant extract the prominent complex with the greatest mobility is a homodimer of mutant MCMl with $\mathrm{P}(\mathrm{PAL})$, and the second major complex is a heterodimer of wild-type MCM1 and mutant MCM1 bound to $\mathrm{P}(\mathrm{PAL})$. Very little of the wild-type MCM1 homodimer $\mathrm{P}(\mathrm{PAL})$ complex is observed because mutant MCM1 monomer is more abundant than the wild-type MCM1 monomer. In fact, titration experiments revealed that the extract with MCM1 $(1-187)$ contained $\sim 5-10$ times as much $\mathrm{P}(\mathrm{PAL})$-binding activity as did the wildtype extract (data not shown), and Western analysis confirmed that the mutant protein was more abundant than the wild-type protein (see Fig. 2). Western analysis also revealed that MCM1 (1-157) was slightly more abundant than wild-type MCMI. The interpretation of the nature of the complexes formed fits the data well for the MCM1 (1-157) extract. In the case of the MCM1 $(1-187)$ extract, a minor high mobility band is observed just below the prominent band; the origin of the minor band is uncertain.

\section{Anti-MCM1 antibodies affect the mobility of PRTF- $P(P A L)$ complexes}

The experiments described above demonstrate that mutant MCM1 molecules are capable of binding to P-box sequences such as $\mathrm{P}(\mathrm{PAL})$, at least when overproduced. Is wild-type $\mathrm{MCMl}$ part of the PRTF-P(PAL) complex detected using extracts prepared from wild-type cells (Fig. 1, lane 2)? In other words, is PRTF the product of MCM1?

To probe the makeup of the observed DNA-protein complexes, we raised antibodies against MCM1 peptides conjugated to BSA (for details, see Materials and methods). An MCM1 internal peptide (MIP), which contains 17 residues of MCMl (amino acids 139-155), stimulated the production of antibodies, whereas an aminoterminal peptide (MNP), which contains the first 19 amino acids of MCM1, did not yield useful antibodies. Nonetheless, the MNP peptide served as a control in bandshift experiments described below. Western analysis using affinity-purified antibodies raised against the MIP/BSA conjugate revealed that there is a single protein species present in extracts of wild-type cells that reacts with the antibodies (Fig. 2). The apparent molecular mass of this species is $37 \mathrm{kD}$, similar to the $32.8 \mathrm{kD}$ predicted by the MCM1 gene sequence (Passmore et al.

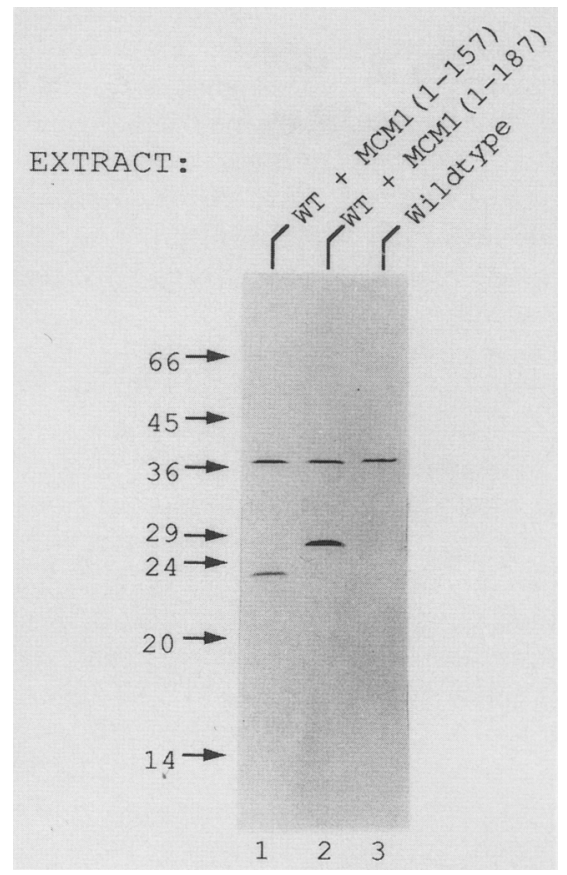

Figure 2. Antibodies to the MIP peptide are specific for MCM1. Western analysis of extracts of wild-type strain SY1378 harboring YEp24 (no MCM1) (lane 3), MSE24 [MCM1 (1-187) (lane 2), or MSB24 [MCM1 (1-157) (lane 1)], using antibodies affinity-purified to MIP-Sepharose (see Materials and methods), was performed as described in Materials and methods [(WT) wild type]. These extracts were prepared by boiling the cells in protein sample buffer (Laemmli 1970). Similar results were obtained with extracts prepared as for bandshift assays.

1988). This species is almost certainly MCM1 because it is more abundant in extracts prepared from cells harboring the MCM1 gene on a multicopy plasmid (data not shown). Extracts that contained MCM1 (1-187) or MCM1 (1-157), in addition to wild-type MCM1, had a second protein species that reacts with the antibodies. MCM1 (1-187) has an apparent molecular mass of 28 $\mathrm{kD}$ (predicted to be $21.2 \mathrm{kD}$ ) and is about five times more abundant than wild-type MCM1. MCM1 (1-157) $(24 \mathrm{kD}$; predicted to be $17.8 \mathrm{kD}$ ) is only slightly more abundant than wild-type MCM1. Thus, the antibodies recognize MCM1 and the two mutant derivatives specifically.

The anti-MIP antibodies were included with incubations of yeast extracts and $\mathrm{P}(\mathrm{PAL}) \mathrm{DNA}$ to determine whether the antibodies affected the nature of the protein-DNA complex formed. Initially, we used extracts that contained a high concentration of MCM1 (1-187) to characterize the properties of the anti-MIP antibodies. Antibodies bound to MCM1 (1-187) might inhibit formation of the complex or might allow for the formation of a ternary MCM1 (1-187)/P(PAL)/antibody complex, which should be reflected by an increase in the molecular weight of the complex.

Figure 3 demonstrates that the anti-MIP antibodies did react with MCM1 (1-187) in bandshift experiments. Lane 2 shows the MCM1 (1-187) shift seen pre- 


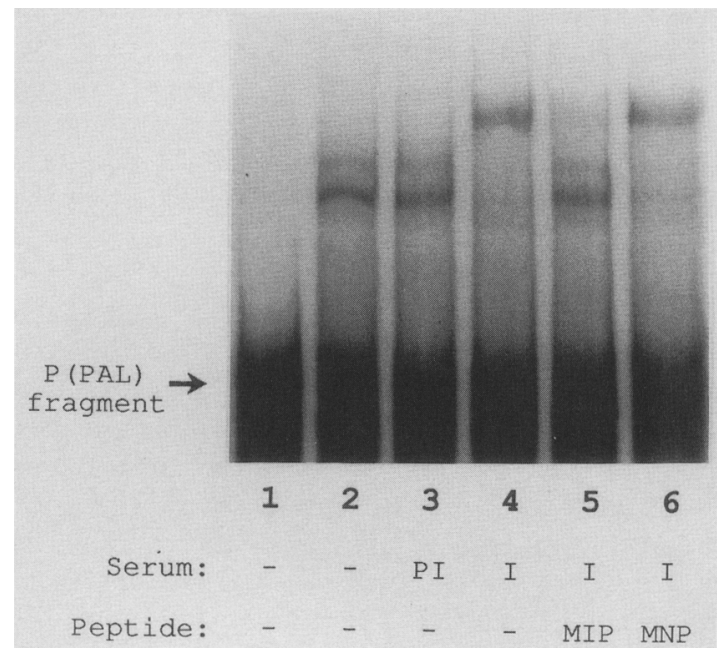

Figure 3. Antibodies to an MCMl peptide recognize the $\mathrm{P}(\mathrm{PAL})$ bound complex when MCM1 (1-187) is overexpressed. Bandshifts were performed using the $\mathrm{P}(\mathrm{PAL})$-containing DNA fragment and an extract from a strain carrying plasmid MSE24, which overproduces MCM1 (1-187). Lanes 1-6 contain the following: no extract (lane 1); fragment incubated with extract (lane 2); extract incubated with preimmune serum (PI) before incubation with fragment (lane $3 \mid$; extract preincubated with affinity-purified antibodies (I) (lane 4); affinity-purified antibodies preincubated with peptide MIP before incubation with extract (lane 5); same as lane 5, but peptide used was MNP (lane 6). (For details of reactions, see Materials and methods.) Decreased mobility in lanes 4 and 6 indicates a specific binding of the antibody to the complex.

viously. This shift was unaffected by preincubation of the extract with preimmune serum (lane 3), but the complex was shifted to a higher position on the gel when the extract was preincubated with the affinity-purified antibodies (lane 4) or immune serum (data not shown). The specificity of this antibody reaction was demonstrated by preincubation of the antibodies with peptides. The peptide MIP, to which the antibodies were raised, prevented the additional shift (lane 5), presumably by blocking recognition sites on the antibodies. The second peptide, MNP, did not have this effect; the antibody-induced shift was seen once again (lane 6).

The results described above reveal that the anti-MIP antibodies can recognize the MCM1 (1-187) protein when it is bound to $\mathrm{P}(\mathrm{PAL})$ in a bandshift experiment. To determine whether PRTF, the protein bound to $\mathrm{P}(\mathrm{PAL})$ in the absence of MCM1 (1-187) overexpression, also can be bound by the anti-MIP antibodies, we used an extract prepared from wild-type cells containing only the vector YEp24; this extract shifted $\mathrm{P}(\mathrm{PAL})$ as before (Fig. 4, lane 2). The PRTF-P(PAL) complex shifted to an even higher position in the presence of affinity-purified antibodies (lane 4) but not in the presence of preimmune serum (lane 3). In addition, the peptide MIP inhibited this further shift, whereas the peptide MNP did not, revealing the specificity of the antibody recognition (lanes 5 and 6). Thus, PRTF, defined as the factor that binds to $\mathrm{P}(\mathrm{PAL})$ in vitro, shares an epitope with MCM1. This suggests that PRTF is the product of the chromosomal MCM1 gene.

\section{Anti-MIP antibodies recognize the $\alpha 1-P R T F$ complex formed at the STE3 UAS}

Studies using antibodies to MIP have provided evidence that the product of the chromosomal MCM1 gene binds to the artificial sequence $\mathrm{P}(\mathrm{PAL})$. In addition to binding $\mathrm{P}(\mathrm{PAL})$, PRTF binds cooperatively with the $\alpha 1$ product of $M A T \alpha$ to the P boxes of $\alpha$-specific UAS elements (Bender and Sprague 1987; Jarvis et al. 1988; Tan et al. 1988). These UAS elements contain forms of the $P$ box in which the symmetry is disrupted by sequence changes in one of the dyads, and they contain an adjacent $Q$ box also. Both the $\mathrm{Q}$ and $\mathrm{P}$ boxes are required for cooperative binding of $\alpha 1$ and PRTF in vitro and for UAS activity in vivo.

To determine whether MCM1 is part of the complex that forms on the QP box DNA of an $\alpha$-specific UAS, the ability of anti-MIP antibodies to retard the mobility of the $\alpha 1 /$ PRTF/DNA complex was assessed using a DNA fragment that contains the 26-bp STE3 sequence (from plasmid pSL905; see Materials and methods). The extract used was made from galactose-grown cells carrying pGAL-MAT 1 (pSL599; Bender and Sprague 1987) because overexpression of $\alpha 1$ is necessary to see the PRTF- $\alpha 1$ DNA complex (Fig. 5A; see also Bender and Sprague 1987). Once again it is clear that mobility of the complex decreased after preincubation of the extract with anti-MIP serum (Fig. 5B, lane 4) but not after treatment with preimmune serum (lane 3). The peptide MIP inhibited this shift (lane 5), whereas the peptide MNP did not (lane 6). Thus, a component of the complex that binds to the STE3 UAS in the presence of $\alpha 1$ shares an epitope with the MCM1 protein, again suggesting that MCM1 is part of that complex.

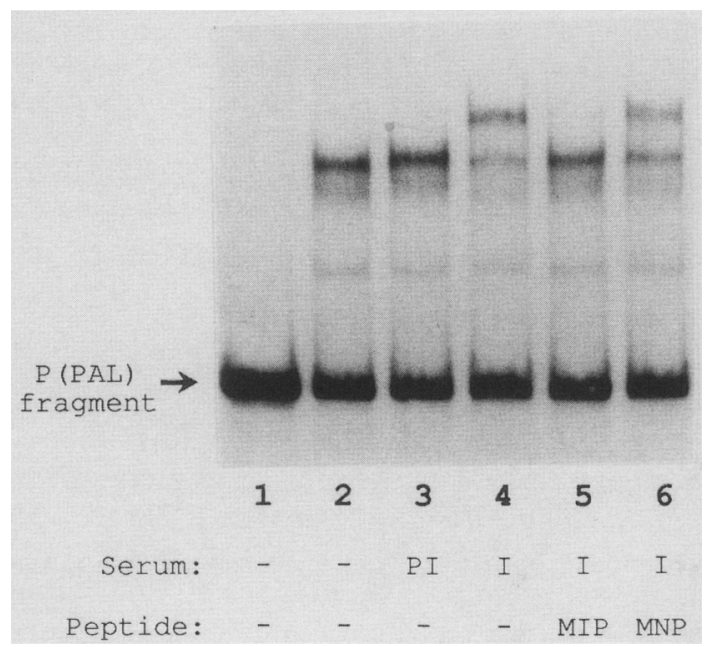

Figure 4. Antibodies to an MCM1 peptide recognize the native PRTF complex formed at $\mathrm{P}(\mathrm{PAL})$. The experiment was performed exactly as in Fig. 3, except that the extract used was from a strain bearing only the control plasmid YEp24. (For details and explanation of each lane, see legend to Fig. 3 and Materials and methods|. 


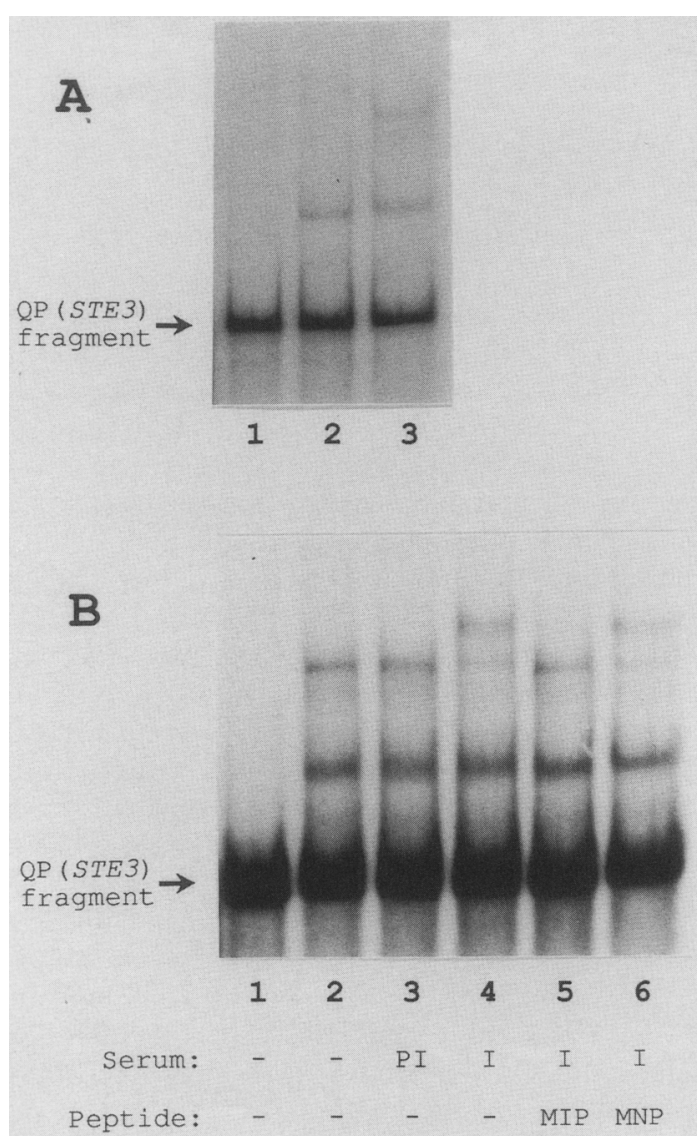

Figure 5. A component of the complex formed on the 26-bp STE3 UAS is recognized by antibodies to an MCM1 peptide. $(A)$ Bandshift of a DNA fragment (171 bp) containing QP(STE3) (26bp UAS). Lane 1 contains no extract; extract of lane 2 was from a $M A T \alpha$ strain bearing YEp24; extract of lane 3 was from the same strain bearing pSL599 (pGAL-MATa1). A demonstrates that the upper band is dependent on the overexpression of $\alpha 1$ and is presumably the $\alpha 1-P R T F$ complex at the PQ sequences (see also Bender and Sprague 1987). The origin of the strong band of intermediate mobility is unknown. $(B)$ The experiment was performed exactly as in Fig. 3, except that the QP(STE3) DNA fragment was used and the extract was from a strain bearing the plasmid pSL599 (as in A, lane 3). In addition, cellwashed immune serum was used instead of affinity-purified antibodies. (For details of sera and peptides, see legend to Fig. 3 and Materials and methods).

\section{MCM1 overexpression stimulates activity conferred by} the STE3 UAS

The experiments described above indicate that certain truncations of MCMl are capable of binding to P-box sequences in vitro. To learn whether MCM1 acts in vivo at the STE3 UAS and whether the truncated MCM1 proteins are competent to activate transcription, we assayed expression of lacZ reporter genes in cells harboring multicopy plasmids that contained either wild-type MCM1 or the MCM1 deletions. Two reporter genes were used; one placed lacZ under the control of the 26-bp STE3 UAS [denoted as QP(STE3); see Bender and Sprague 1987; Jarvis et al. 1988]; the other placed lacZ under the control of $\mathrm{P}(S T E 3)$. By itself, $\mathrm{P}(S T E 3)$ is inactive as a UAS
(Jarvis et al. 1988) and has been shown to have a 50-fold reduced affinity for PRTF compared with $\mathrm{P}(\mathrm{PAL})$ (Bender and Sprague 1987). If MCM1, in fact, binds to P boxes in vivo, then high concentrations of MCM1 proteins might favor the formation of the protein-DNA complex, according to the laws of mass action, and thereby stimulate expression.

Indeed, overexpression of wild-type $M C M 1$ protein stimulated expression directed by QP(STE3) (Table 1). Stimulation was seen in both $\alpha$ and a cells; however, the added activity was greater in $\alpha$ cells, implying that the protein is able to interact with $\alpha$ l. Furthermore, overexpression of wild-type MCM1 also stimulated expression of lacZ under the control of just P(STE3). The degree of stimulation was comparable in $\alpha$ and a cells, as expected, because the Q box is necessary for increased expression mediated by $\alpha 1$. The truncated proteins, MCM1 $(1-187)$ and MCM1 (1-157), were effective also in stimulating expression of $l a c Z$ under the control of QP(STE3) or $\mathrm{P}(S T E 3)$ (Table 1). The effects of these truncated MCM1 molecules, however, were somewhat less dramatic than that of the full-length MCM1. The third truncation, MCM1 (1-91), which could not bind to DNA in vitro, also could not activate transcription in vivo. Finally, in control experiments, none of the MCM1 molecules increased significantly the expression of reporter $l a c Z$ genes under the control of the CYC1 UAS (pSL330) or lacking a UAS (pSL709).

\section{Discussion}

Previous work (Bender and Sprague 1987; Tan et al. 1988 ) has shown that a protein (or proteins) present in all three cell types of yeast is capable of binding to P-box sequences. This protein, termed PRTF, is thought to be involved in expression of $\alpha$ - and a-specific genes and probably other genes as well. In this paper we identified the likely structural gene for PRTF by relying on the two biochemical properties that were used to define PRTF activity. In particular, PRTF had been shown to bind efficiently in vitro to symmetrical sequences such as $\mathrm{P}(\mathrm{PAL})$. In contrast, PRTF could bind efficiently to the P box of the STE3 UAS only if $\alpha 1$ was present in the binding reaction. These in vitro data support the model for $\alpha$-specific gene expression proposed by Jarvis et al. (1988). According to this model, PRTF is a transcription activator. It can bind unaided to the symmetric $\mathrm{P}(\mathrm{PAL})$ sequence, and hence this sequence acts in vivo as a UAS that is not cell-type-specific. On the other hand, the P-box components of $\alpha$-specific UAS elements are not symmetric. Optimal binding of PRTF to the $\alpha$-specific UASs requires cooperative interaction with $\alpha \mathrm{l}$ and a second sequence element, the $\mathrm{Q}$ box. The role of $\alpha 1$ may simply be to assist the binding of PRTF or it may induce conformational changes in PRTF as well.

The previous work left the identity and character of PRTF a mystery. The work described here suggests that PRTF is encoded by a known gene, MCM1. This statement is supported by three lines of evidence. (1) Two different truncations of MCM1 form complexes of 
Table 1. MCM1 overexpression elevates $\beta$-galactosidase activity conferred by STE3 upstream activation sequence elements

\begin{tabular}{|c|c|c|c|c|c|c|}
\hline \multirow{3}{*}{$\begin{array}{l}\text { Plasmid-borne } \\
\text { MCM1 }\end{array}$} & \multicolumn{6}{|c|}{ Upstream activation sequence } \\
\hline & \multirow{2}{*}{$\begin{array}{l}\text { None } \\
\text { (pSL709) } \\
M A T \alpha\end{array}$} & \multirow{2}{*}{$\begin{array}{l}\text { CYC1 } \\
\text { (pSL330) } \\
M A T \alpha\end{array}$} & \multicolumn{2}{|c|}{$\begin{array}{l}\mathrm{QP}(S T E 3) \\
\text { (pSL905) }\end{array}$} & \multicolumn{2}{|c|}{$\begin{array}{r}\mathrm{P}(S T E 3) \\
\text { (pSL719) }\end{array}$} \\
\hline & & & $\overline{M A T \alpha}$ & $\overline{M A T \mathbf{a}}$ & $\overline{M A T \alpha}$ & $M A T \mathbf{a}$ \\
\hline $\begin{array}{l}\text { None } \\
\text { (YEp24) }\end{array}$ & 29 & 920 & 610 & 20 & 40 & 44 \\
\hline $\begin{array}{c}\text { MCM1 (1-286) } \\
\text { (pED629/2) }\end{array}$ & 42 & 450 & 1510 & 150 & 520 & 560 \\
\hline $\begin{array}{l}\text { MCM1 (1-187) } \\
\text { (MSE24) }\end{array}$ & 42 & 710 & 1130 & 140 & 350 & 460 \\
\hline $\begin{array}{l}\text { MCMI (1-157) } \\
\text { (MSB24) }\end{array}$ & 40 & 780 & 910 & 110 & 360 & 410 \\
\hline $\begin{array}{l}\text { MCM1 (1-91) } \\
\text { (MSS24) }\end{array}$ & 32 & 1060 & 400 & 20 & 31 & 37 \\
\hline
\end{tabular}

Numbers reported are units of $\beta$-galactosidase (modified Miller units). See Materials and methods for details of assays, MCM1 plasmids, and reporter plasmids. Each value is the mean of assays performed on at least three independent transformants. The plasmids reside in the isogenic MATa and MATa derivatives of HR125-5d.

different mobilities on $\mathrm{P}(\mathrm{PAL})$, suggesting that $\mathrm{MCM} 1$ binds to $\mathrm{P}(\mathrm{PAL})$. (2) Antibodies raised to an internal peptide of MCM1 bind specifically to the complexes present at $\mathrm{P}(\mathrm{PAL})$ and at the STE3 UAS in vitro. (3) Overexpression of wild-type or truncated derivatives of MCM1 stimulates the expression conferred by STE3 UAS elements in vivo. These results, taken together with the lowered expression of the $\alpha$-specific genes seen in the mcm1-1 mutant (Passmore et al. 1988), strongly suggest that MCM1 encodes, at least in part, the factor we have called PRTF. The number of distinct protein species that actually comprises PRTF is not known.

Two other groups have reached this conclusion also. Keleher et al. (1988) identified and partially purified a factor, termed GRM, that binds to the P-box sequences found in $\alpha 2$ operator sites of a-specific genes. GRM binds the $\alpha 2$ operator cooperatively with $\alpha 2$. The P-box part of the operator, however, is sufficient itself to bind GRM and to activate transcription in vivo. These findings suggest that GRM is the same as PRTF, which we have proposed activates a-specific genes via their $P$ boxes (Jarvis et al. 1988). Moreover, using an approach that parallels the experiments reported in this paper, C.A. Keleher and A.D. Johnson (pers. comm.) have shown that antibodies against MCMI react with the GRM biochemical activity. Likewise, Hayes et al. (1988) have shown that the antibody preparation used by Keleher and Johnson reacts with a yeast protein, presumably PRTF/GRM, that binds to P-box sequences. Therefore, the conclusion that MCM1 encodes PRTF/GRM seems firm.

What features of the MCM1 sequence might give information about its mode of action? The MCM1 polypeptide is predicted to be 286 amino acids long and has several notable features (diagramed in Fig. 6; see Dubois et al. 1987b; Passmore et al. 1988), including an acidic stretch of amino acids and three polyglutamine tracts. Such features commonly are found as part of regulatory proteins from yeast and other organisms, and in some cases these features have been shown to be important for the function of the regulatory protein /GAL4, Keegan et al. 1986; GCN4, Hope and Struhl 1986; Sp1, Courey and Tjian 1988; HAP1, Pfeifer et al. 1989). It is noteworthy that the results presented above demonstrate that the first 157 amino acids of MCM1, which contains the acidic stretch and only one of the three polyglutamine tracts, was sufficient when overexpressed to serve as an activator of transcription at the STE3 $\mathrm{P}$ box. A truncation that left only the first 91 amino acids, however, did not bind DNA in vitro and was inactive for transcription activation in vivo; this truncation removed the acidic stretch in addition to all of the polyglutamine regions.

An MCMI homolog recently has been implicated in

Binding Activation

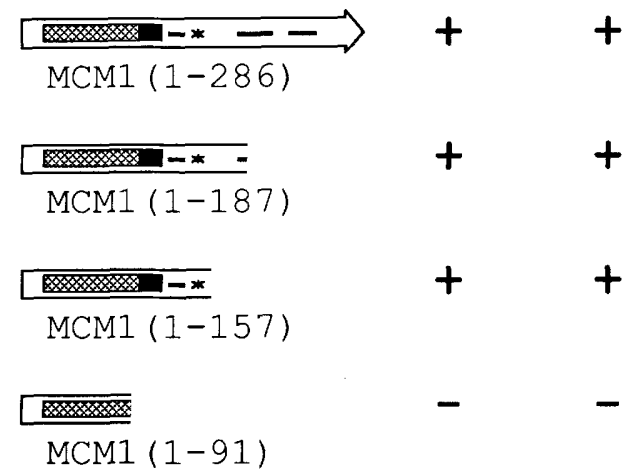

Figure 6. Features of the wild-type and truncated MCMl proteins (features adapted from Passmore et al. 1988). The open reading frame (ORF) corresponding to the MCM1 product is depicted as an open arrow. Within the arrow, the solid block indicates a stretch of acidic amino acids, the lines indicate polyglutamine tracts, and the crosshatched box represents the region of homology between MCM1 and SRF. The sequence corresponding to the peptide MIP is shown by an asterisk (*). The extent of the ORF that remains in each of the MCM1 deletions is indicated below the full-length MCM1 ORF. 
the expression of genes in mammalian cells. Transcriptional induction in response to growth factors is mediated by the serum response element (SRE) sequence, a relative of the $\mathrm{P}$ box, found upstream of many genes such as c-fos (e.g., see Norman et al. 1988). A serum response factor (SRF), which shows homology to MCM1 (55 amino acids in a stretch of 81 are identical), has been identified that binds to such sequences and is able to promote a constitutive level of transcription in vivo (Norman et al. 1988). The known biochemical properties of SRF are insufficient to explain the complex regulation of the serum-inducible genes, however (Norman et al. 1988). Thus, the SRF-SRE system may employ modulators of SRF functions analogous to $\alpha 1$ and $\alpha 2$ to achieve this regulation.

The versatility of the yeast MCM1/P-box system is remarkable. An MCM1-binding site, $\mathrm{P}(\mathrm{PAL})$, acts as an unregulated UAS element. By a slight modification of the $P$ box and addition of a Q box, the UAS becomes an $\alpha 1-$ MCMl site, rendering gene expression $\alpha$-specific. By flanking the P box with an $\alpha 2$ operator, an $\alpha 2-\mathrm{MCM} 1$ site is created, conferring a-specific gene expression. Thus, a single protein can function as a generic transcription activator, as a cell-type-specific activator (in conjunction with $\alpha 1)$, and as a cell-type-specific repressor (with $\alpha 2$ ). It seems likely that homologs to the MCMl/P-box system that are found in other species will show this same versatility.

\section{Materials and methods}

Strains and media

The isogenic MATa and MAT $\alpha$ versions of strain HR125-5d (leu2-3, -112 his3 his4 trp1 ura3-52, provided by R. Jensen and I. Herskowitz) have been described (Jarvis et al. 1988). Strain SY1378 (provided by B. Stevenson) is a pep4 :: URA3 derivative of the MAT $\alpha$ strain 246-1-1 (Siliciano and Tatchell 1984); other markers are leu2, ura3, trp1, his $3 \Delta 200::$ ura3, and can1.

The yeast media YPD and SD, as well as indicated supplements, have been described (Sherman et al. 1982). Simultaneous selection for LEU2- and URA3-bearing plasmids was achieved by growing cells in SD-Leu-Ura (SD supplemented with adenine, L-tryptophan, L-histidine, L-arginine, L-methionine, L-tyrosine, L-lysine, L-phenylalanine, and L-threonine) (Sherman et al. 1982). SGal/Raf-Ura is the same as SD-Ura, except that the dextrose was replaced by $3 \%$ galactose and $2 \%$ raffinose.

\section{Plasmids and DNA manipulations}

Standard methods (Maniatis et al. 1982) were used for DNA preparations, bacterial transformations, and plasmid constructions. DNA sequencing was performed by the dideoxy method (Sanger et al. 1977).

CYC1-lacZ reporter plasmids are depicted in Figure 7. Control plasmid pSL330, which contains CYC1-lacZ adjacent to the native CYC1 UAS is described by Jarvis et al. (1988). Plasmid pSL709 (constructed by D. Hagen) is a derivative of pSL351 (Jarvis et al. 1988) in which the XhoI-SphI fragment of CYC1 was replaced by a polycloning site derived from M13mp18 (Yanisch-Perron et al. 1985). This region is shown as a thin bar in Figure 7 and bears the restriction sites (from left to right) EcoRI, XhoI, EcoRI, SacI, KpnI, SmaI, BamHI, XbaI, SalI,

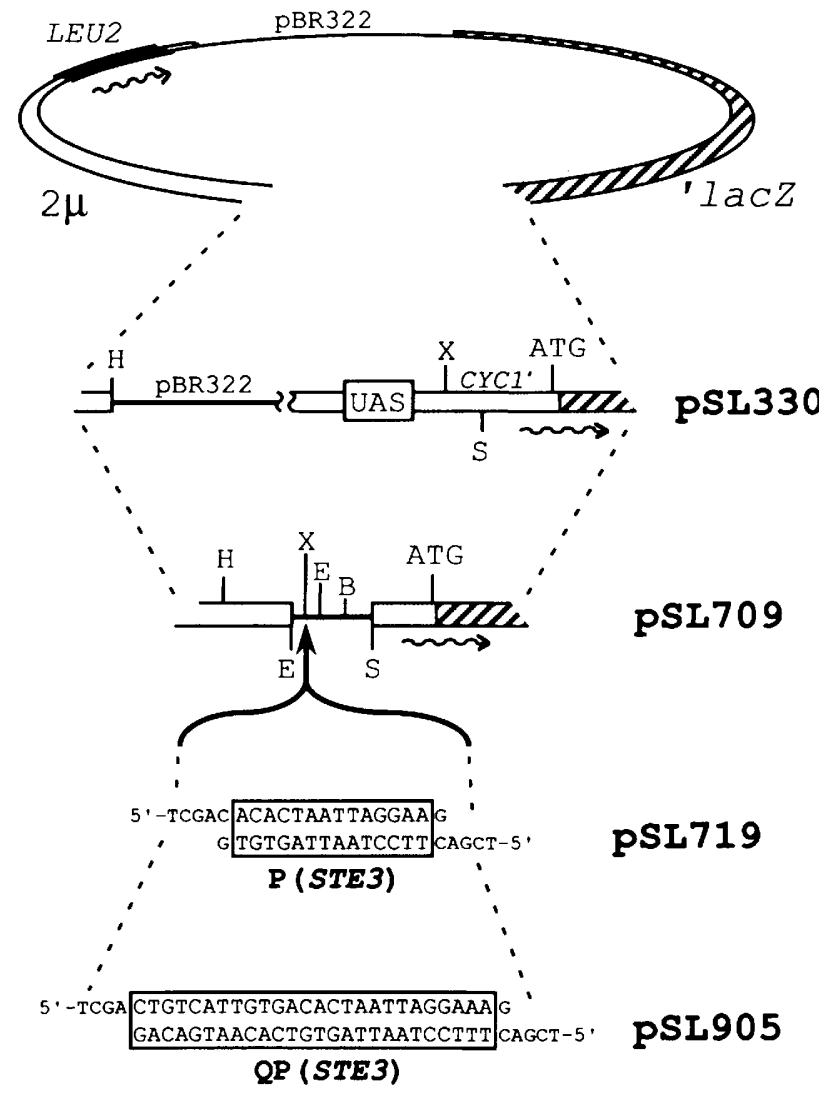

Figure 7. lacZ reporter plasmids. The plasmid pSL330, which carries the CYC1 UAS, was described previously (Jarvis et al. 1988). Part of the CYC1 (stippled box) transcriptional start region has been replaced by a polycloning site in plasmid pSL709 (provided by D. Hagen; see text). Plasmids pSL719 and pSL905 were derived by insertion of the synthetic oligonucleotides $\mathrm{P}(S T E 3)$ and $\mathrm{QP}(S T E 3)$, respectively, into the XhoI site of pSL709. Actual orientation of the oligonucleotides is as shown. Plasmids are not drawn precisely to scale. Wavy arrows indicate mRNA; the ATG start codon, derived from CYC1, is marked. Restriction sites marked are not necessarily unique in the plasmid. (H) HindIII; (X) XhoI; (S) SphI; (E) EcoRI; (B) BamHI.

PstI, and SphI. Plasmid pSL 719 was derived from pSL709 by insertion of the SalI-ended synthetic duplex oligonucleotide $\mathrm{P}(S T E 3)$. Plasmid pSL905 was constructed (by J.-J. HwangShum) by insertion of the Sall-ended duplex oligonucleotide $\mathrm{QP}($ STE3). The boxed sequence (Fig. 7) corresponds to the $\mathrm{P}$ and $\mathrm{Q}$ box of the STE3 UAS from -343 and -318 relative to the STE3 ATG. Oligonucleotides were synthesized at the University of Oregon Biotechnology Lab, using an Applied Biosystems model 380B DNA synthesizer (phosphoramidite chemistry).

The $\mathrm{P}(\mathrm{PAL})$-containing fragment used in the electrophoresis mobility-shift assays was obtained from plasmid pSL717 as a 160-bp HindIII-BamHI fragment; pSL 717 is identical to pSL719 (Fig. 7), except that the inserted oligonucleotide carries the P(PAL) sequence 5'-TTCCTAATTAGGAA-3' (see Jarvis et al. 1988). The STE3 26-bp UAS [QP(STE3)] was isolated as a 171-bp HindIII-BamHI fragment from plasmid pSL905. Fragments were purified by agarose gel electrophoresis, followed by electroelution or treatment with Gene Clean (Biol0l, Inc.), used according to the manufacturer's recommendations. Fragments were made radioactive by filling in the BamHI and HindIII ends 
using the Klenow fragment of DNA polymerase I (BoehringerMannheim) and high specific activity $\left[\alpha^{-32}\right.$ P]dCTP (New England Nuclear).

Plasmid pED629/2 (kindly provided by Francine Messenguy) contains the entire MCM1 gene and has been described by Dubois et al. (1987a). Other MCM1-containing plasmids were constructed as follows. Plasmid pED629/3 (Dubois et al. 1987a) carries two copies of a 2-kb fragment, one at each EcoRI site of the plasmid pFL1, a multicopy vector closely related to YEp24 (Botstein et al. 1979). This 2-kb fragment encodes a truncated form of $M C M 1$, retaining codons 1-187. To ease subsequent cloning manipulations, the 2-kb EcoRI-EcoRI fragment was made flush using T4 DNA polymerase and ligated into the HincII site of plasmid pUC19 (Yanisch-Perron et al. 1985) to form plasmid MEE19. The fragment was oriented with the $B s s \mathrm{H} 2$ site close to the XbaI site of pUC19. MSE19, which encodes MCM1 (1-187), was derived as an SphI shrink of MEE19. DNA sequencing confirmed that a termination codon immediately follows codon 187 , as expected, given the cloning manipulations that created MSE19 and MEE19. MSS19 was created by inserting a $\mathrm{XbaI}$ linker $15^{\prime}$-TGCTCTAGAGCA; New England Biolabs) into the StuI site at MCM1 nucleotide position 272 (from the A in the ATG) in plasmid MSE19; the plasmid then was cut with $X b a I$ and religated to eliminate downstream $M C M 1$ sequences. The $X b a I$ linker provided two non-MCM1 codons and a stop codon after the 91st amino acid of MCM1. Plasmid MSB19 was constructed by inserting a BglII linker (5'GGAAGATCTTCC; New England Biolabs) into the T4 DNA polymerase-filled BssH2 site of MCM1 (position 467 from the ATG) in plasmid MSE19. The Escherichia coli lacZ gene was inserted into this BglII site as a 3-kb BamHI-BamHI fragment from plasmid pMC1871 (Casadaban et al. 1980). Although the intention was to create an MCM1-lacZ gene fusion, an error in the published sequence of $M C M 1$ (Dubois et al. 1987b), resulted in the creation of an out-of-frame lacZ fusion (confirmed by sequence analysis); the MCM1 reading frame can be extended for only nine amino acids before reaching a stop codon. Therefore, plasmid MSB19 encodes MCM1 (1-157).

$M C M 1$ constructs were cloned into yeast plasmids by cutting at the SphI and BamHI sites of the pUC19 polycloning site, purifying the fragments, and ligating into BamHI-SphI cut YEp24 (Botstein et al. 1979), creating plasmids MSE24, MSS24, and MSB24 (Fig. 8). This placed all of the constructs in the same orientation in the tet gene.

Plasmid pSL599 contains a GAL1-MAT 1 gene fusion on a URA3 $2 \mu$ vector (Bender and Sprague 1987).

\section{$\beta$-Galactosidase assays}

Yeast strains carrying reporter plasmids were converted to spheroplasts (Beggs 1978) and transformed with plasmids that contained MCM1. Three transformants of each were streak-purified on SD-Leu-Ura, single colonies were patched on SD-LeuUra, and liquid SD-Leu-Ura overnight cultures were grown at $30^{\circ} \mathrm{C}$. Overnight cultures were diluted 10 -fold into SD-Leu-Ura and grown for $5 \mathrm{hr}$ at $30^{\circ} \mathrm{C}$. Then cells were permeabilized and $o$-nitrophenyl- $\beta$-D-galactoside assays were performed as described (Jarvis et al. 1988; modified from Miller 1972).

\section{Preparation of anti-MCM1 antibodies}

An MCM1 MNP and an MIP were synthesized with the sequences $\mathrm{NH}_{2}$-MSDIEEGTPTNNGQQKERRYC-COOH and $\mathrm{NH}_{2}$-KNAHANSLGHLNQDQVPAAR-COOH, respectively. Underlined residues correspond to the derived $\mathrm{MCM} 1$ protein sequence from amino acids $1-19$ and 139-155, respectively. Peptides were synthesized by the University of Oregon Biotechnology Lab and Vega Biochemicals. Peptides were conjugated to bovine serum albumin (BSA) (fraction V, Sigma) by the methods of Kagen and Glick (1979), using the benzidine method for MNP and the glutaraldehyde method for MIP. Female rabbits were injected intradermally with 40 or $120 \mu \mathrm{g}$ of the BSA/peptide conjugate emulsified in complete Freund's adjuvant (GIBCO). Rabbits were given booster injections every 6 weeks, with one-half of the original amount of antigen emulsified in incomplete Freund's adjuvant. Sera used in this work were obtained 2 weeks after the boost. Sera from rabbits injected with the MNP/BSA conjugate reacted with MNP/BSA but did not appear to react with MCM1 in Western analysis or in mobilityshift assays (data not shown); therefore, they were not pursued further. Before use in Western analysis or binding assays, sera were washed with whole yeast cells, essentially by the method of Rothman et al. (1986). One milliliter of serum was incubated twice with $\sim 50 \mathrm{OD}_{600}$ of washed yeast cells (strain HR125-5d $\alpha$ ) for $30 \mathrm{~min}$ at $0^{\circ} \mathrm{C}$; serum was cleared of yeast cells by centrifugation.

Antibodies to MIP were affinity-purified essentially as described in the Pharmacia booklet Affinity chromatography. Ten milligrams of MIP were coupled to cyanogen-bromide-activated Sepharose (Sigma), and $13 \mathrm{ml}$ of serum obtained 4 weeks after the boost was applied to the column. The specific antibodies were eluted from the column, and the purification was repeated. The twice-purified antibodies were concentrated to a volume of $1 \mathrm{ml}$. BSA was added to $1 \mathrm{mg} / \mathrm{ml}$.

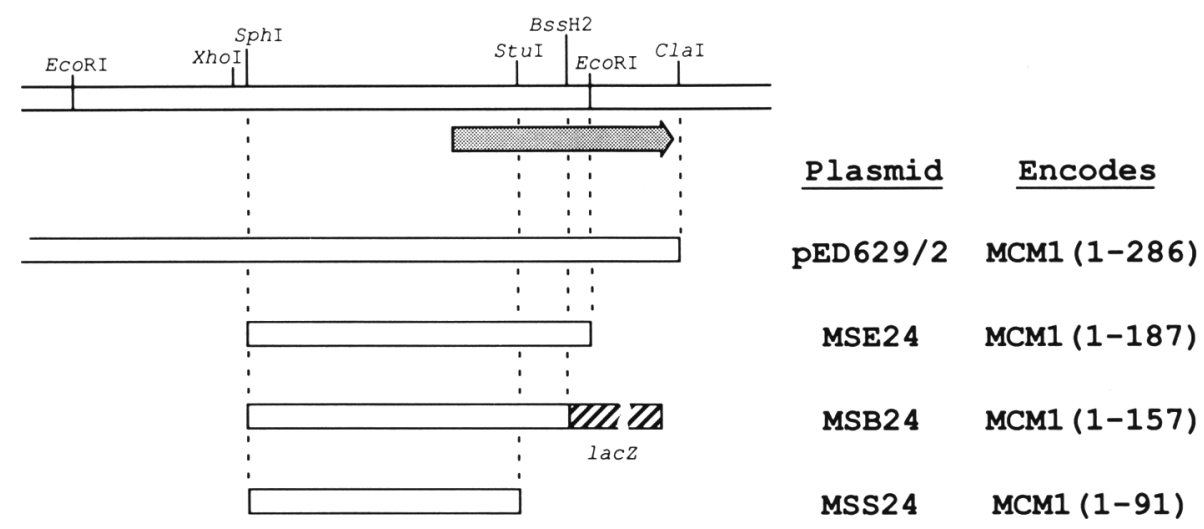

Figure 8. MCM1 plasmids. DNA in the region of $M C M 1$ is shown (top); the ORF of MCM1 is shown as a shaded arrow. Subclones of the DNA containing MCM1 are shown below; manipulations and plasmids are described in the text. 


\section{Western analysis}

Standard protocols for Western analysis of proteins (Burnette 1981) were followed with some modifications. Crude yeast protein extracts were prepared in either of two ways. The first was to harvest exponentially growing cells, suspend them in protein sample buffer (Laemmli 1970), lyse them by repeated boiling and vortex mixing with glass beads, and centrifuge them to remove debris. The second method was identical to the one used to prepare extracts for bandshift assays and is described below. Samples (either $5 \%$ of a sample prepared by the first method or $12 \mu \mathrm{g}$ of yeast protein extract prepared for bandshift assays were subjected to electrophoresis on $15 \%$ SDS-polyacrylamide gels. Proteins were transferred in a Hoefer transfer apparatus onto nitrocellulose membranes using Towbin buffer (Towbin et al. 1979) with $0.01 \%$ SDS. Primary antibody consisted of whole-cell-washed serum or affinity-purified antibodies (see above) diluted $1: 100$ or $1: 200$ into antibody buffer $11.5 \%$ nonfat milk; Carnation). Secondary antibody was goat antirabbit IgG conjugated to alkaline phosphatase (BoehringerMannheim) diluted 1:1250 in antibody buffer; blots were developed with Promega color development reagents.

\section{Protein extracts}

Crude protein preparations (extracts) were made from plasmidbearing yeast strains as follows; the pep 4 mutant strain SY 1378 was used in all cases as the plasmid recipient. One hundredmilliliter cultures of strains with MCM1 plasmids were grown in SD-Ura to $\sim 2 \mathrm{OD}_{600}$. The pSL599 (pGAL-MAT $\alpha 1$ )-containing strain was grown overnight in SD-Ura, cells were washed to remove glucose, and a $100-\mathrm{ml} \mathrm{SGal/Raf-Ura} \mathrm{culture}$ was inoculated to a density of $\sim 0.1 \mathrm{OD}_{600}$; the culture was grown to a density of $\sim 1 \mathrm{OD}_{600}(\sim 50 \mathrm{hr})$. Extracts were prepared essentially as described in Bender and Sprague (1987), except that cells were lysed using glass beads (Rothman et al. 1986). After a water wash of the cell pellets, the cells were resuspended in a volume (in milliliters) of A300 [buffer A [0.02 M $\mathrm{NaPO}_{4}$ (pH 7.3), 1 mM EDTA, 1 mM DTT, 5\% glycerol] with $300 \mathrm{~mm} \mathrm{NaCl}$ ] equal to the pellet weight (in grams) $\times 2.5$. Phenylmethylsulfonyl fluoride was added to $10 \mu \mathrm{g} / \mathrm{ml}$, and 2.5 grams of glass beads (Sigma; $\sim 300-\mu \mathrm{m}$-diameter, acid washed) were added per milliliter of A300 used. Cells with glass beads were kept cold and mixed (Vortex mixer) at top speed eight times for $30 \mathrm{sec}$ each. Liquid was drawn out and centrifuged in a microcentrifuge for $15 \mathrm{~min}$ to remove remaining glass beads. Ammonium sulfate precipitation, dialysis, storage, and protein concentration determinations were as described (Bender and Sprague 1987).

\section{DNA-binding assays}

Electrophoresis mobility-shift assays (bandshifts) were carried out essentially as described by Bender and Sprague (1987) (see also Fried and Crothers 1981; Garner and Revzin 1981). When present, $0.5 \mu \mathrm{l}$ of $0.04 \mu \mathrm{g} / \mu \mathrm{l}$ peptide was incubated for $15 \mathrm{~min}$ at room temperature with $1 \mu l$ of a $1: 16$ dilution of cell-washed serum or affinity-purified antibodies added to $10 \mu \mathrm{l}$ of Al00M (buffer A with $100 \mathrm{~mm} \mathrm{NaCl}$ and $15 \mathrm{mM} \mathrm{MgCl}_{2}$ ). Twelve micrograms of crude yeast extract then was added in a volume of 8 $\mu \mathrm{l}$ (50\% A100, 50\% glycerol) and incubated for $15 \mathrm{~min}$ at room temperature. Approximately $8 \times 10^{-5} \mu \mathrm{g}$ of ${ }^{32} \mathrm{P}$-labeled DNA fragment and $0.3 \mu \mathrm{g}$ of sonicated salmon sperm DNA were added simultaneously in a volume of $2 \mu \mathrm{l}$; reactions were incubated for an additional $20 \mathrm{~min}$ at room temperature and were stopped by loading onto a nondenaturing $4 \%$ polyacrylamide gel. Electrophoresis was performed as described by Bender and Sprague (1987), except that gels were dried without prior fixing.

\section{Acknowledgments}

We are especially grateful to Francine Messenguy for generously providing the MCM1 clone. We thank Cynthia Keleher and Alexander Johnson for communicating results prior to publication, Dave Hagen for comments, and Janet Monday for preparation of the manuscript. Also, we thank Christopher Raymond for providing details about affinity purification of antibodies and $\mathrm{D}$. Hagen for help with sequencing the MCM1 deletions. This work was supported by research (GM-30027) and training (GM-00715) grants from the U.S. Public Health Service and by a Faculty Research Award (FRA-282) from the American Cancer Society to G.F.S. This material also is based on work supported under a National Science Foundation Graduate Fellowship to E.E.J.

\section{References}

Beggs, J.D. 1978. Transformation of yeast by a replicating hybrid plasmid. Nature 275: 104-109.

Bender, A. and G.F. Sprague, Jr. 1987. MAT $\alpha 1$ protein, a yeast transcription activator, binds synergistically with a second protein to a set of cell-type-specific genes. Cell 50: 681-691.

Botstein, D., S.C. Falco, S.E. Stewart, M. Brennan, S. Scherer, D.T. Stinchcomb, K. Struhl, and R.W. Davis. 1979. Sterile host yeasts (SHY): A eukaryotic system of biological containment for recombinant DNA experiments. Gene 8: $17-24$.

Burnette, W.N. 1981. 'Western blotting': Electrophoretic transfer of proteins from sodium dodecyl sulfate-polyacrylamide gels to unmodified nitrocellulose and radiographic detection with antibody and radioiodinated protein A. Anal. Biochem. 112: 195-203.

Casadaban, M.J., J. Chou, and S.N. Cohen. 1980. In vitro gene fusions that join an enzymatically active $\beta$-galactosidase segment to amino-terminal fragments of exogenous proteins: Escherichia coli plasmid vectors for the detection and cloning of translational initiation signals. I. Bacteriol. 143: $971-980$.

Courey, A.J. and R. Tjian. 1988. Analysis of Spl in vivo reveals multiple transcriptional domains, including a novel glutamine-rich activation motif. Cell 55: 887-898.

Dubois, E., J. Bercy, and F. Messenguy. 1987a. Characterization of two genes, $A R G R I$ and $A R G R I I I$ required for specific regulation of arginine metabolism in yeast. Mol. Gen. Genet. 207: $142-148$.

Dubois, E., J. Bercy, F. Deschamps, and F. Messenguy. 1987b. Characterization of two new genes essential for vegetative growth in Saccharomyces cerevisiae: Nucleotide sequence determination and chromosome mapping. Gene 55: 265275.

Flessel, M.C., A.J. Brake, and J. Thorner. 1989. The MFo1 gene of Saccharomyces cerevisiae: Genetic mapping and mutational analysis of promoter elements. Genetics 121: 223236.

Fried, M. and D. Crothers. 1981. Equilibrium and kinetics of lac repressor-operator interactions by polyacrylamide gel electrophoresis. Nucleic Acids Res. 9: 6505-6525.

Garner, M. and A. Revzin. 1981. A gel electrophoresis method for quantifying the binding of proteins to specific DNA regions: Application to components of the $E$. coli lactose regulatory system. Proc. Nat1. Acad. Sci. 81: 6442-6446.

Hayes, T.E., P. Sengupta, and B.H. Cochran. 1988. The human c-fos serum response factor and the yeast factors GRM/ PRTF have related DNA-binding specificities. Genes DeV. 2: 1713-1722. 
Herskowitz, I. 1988. Life cycle of the budding yeast Saccharomyces cerevisiae. Microbiol. Rev. 52: 536-553.

Hope, I.A. and K. Struhl. 1986. Functional dissection of a eukaryotic transcriptional activator protein, GCN4 of yeast. Cell 46: 885-894.

Inokuchi, K., A. Nakayama, and F. Hishinuma. 1987. Identification of sequence elements that confer cell-type-specific control of $M F \alpha 1$ expression in Saccharomyces cerevisiae. Mol. Cell. Biol. 7: 3185-3193.

Jarvis, E.E., D.C. Hagen, and G.F. Sprague, Jr. 1988. Identification of a DNA segment that is necessary and sufficient for $\alpha$-specific gene control in Saccharomyces cerevisiae: Implications for regulation of $\alpha$-specific and a-specific genes. Mol. Cell. Biol, 8: $309-320$.

Johnson, A.D. and I. Herskowitz. 1985. A repressor (MAT $\alpha 2$ product) and its operator control expression of a set of cell type specific genes in yeast. Cell 42: 237-247.

Kagen, A. and M. Glick. 1979. Methods of radioimmunoassay (ed. X. Jaffe and X. Behrman), pp. 328-329. Academic Press, New York.

Keegan, L., G. Gill, and M. Ptashne. 1986. Separation of DNA binding from the transcription-activating function of a eukaryotic regulatory protein. Science 231: 699-704.

Keleher, C.A., C. Goutte, and A.D. Johnson. 1988. The yeast cell-type-specific repressor $\alpha 2$ acts cooperatively with a non-cell-type-specific protein. Cell 53: 927-936.

Khoury, G. and P. Gruss. 1983. Enhancer elements. Cell 33: $313-314$

Kronstad, J.W., J.S. Holly, and V.L. MacKay. 1987. A yeast operator overlaps an upstream activation site. Cell 50: 369-377.

Laemmli, U.K. 1970. Cleavage of structural proteins during the assembly of the head of bacteriophage T4. Nature 227: 680685.

Maine, G.T., P. Sinha, and B.-K. Tye. 1984. Mutants of S. cerevisiae defective in the maintenance of minichromosomes. Genetics 106: 365-385.

Maniatis, T., E.F. Fritsch, and J. Sambrook. 1982. Molecular cloning: A laboratory manual. Cold Spring Harbor Laboratory, Cold Spring Harbor, New York.

Miller, J.H. 1972. Experiments in molecular genetics. Cold Spring Harbor Laboratory, Cold Spring Harbor, New York.

Nasmyth, K. and D. Shore. 1988. Transcriptional regulation in the yeast life cycle. Science 237: 1162-1170.

Norman, C., M. Runswick, R. Pollock, and R. Treisman. 1988. Isolation and properties of cDNA clones encoding SRF, a transcription factor that binds to the $c$-fos serum response element. Cell 55: 989-1003.

Passmore, S., G.T. Maine, R. Elble, C. Christ, and B. Tye. 1988. Saccharomyces cerevisiae protein involved in plasmid maintenance is necessary for mating of MATa cells. I. Mol. Biol. 204: 593-606.

Pfeifer, K., K.-S. Kim, S. Kogan, and L. Guarente. 1989. Functional dissection and sequence of yeast HAP1 activator. Cell 56: $291-301$

Rothman, J.H., C.P. Hunter, L.A. Valls, and T.H. Stevens. 1986. Overproduction-induced mislocalization of a yeast vacuolar protein allows isolation of its structural gene. Proc. Natl. Acad. Sci. 83: 3248-3252.

Sanger, F., S. Nicklen, and A.R. Coulson. 1977. DNA sequencing with chain-terminating inhibitors. Proc. Natl. Acad. Sci. 74: 5463-5467.

Sherman, F., G.R. Fink, and J.B. Hicks. 1982. Methods in yeast genetics. Cold Spring Harbor Laboratory, Cold Spring Harbor, New York.

Sprague, G.F., Jr., L.C. Blair, and J. Thorner. 1983. Cell interactions and regulation of cell type in the yeast Saccharomyces cerevisiae. Annu. Rev. Microbiol. 37: 623-660.
Tan, S., G. Ammerer, and T.J. Richmond. 1988. Interactions of purified transcription factors: Binding of yeast MAT $\alpha 1$ and PRTF to cell type-specific, upstream activating sequences. EMBO /. 7: 4255-4264.

Towbin, H., T. Staehelin, and J. Gordon. 1979. Electrophoretic transfer of proteins from polyacrylamide gels to nitrocellulose sheets: Procedure and some applications. Proc. Natl. Acad. Sci. 76: 4350-4354.

Yanisch-Perron, C., J. Vieira, and J. Messing. 1985. Improved M13 phage cloning vectors and host strains: Nucleotide sequences of the M13mp18 and pUC19 vectors. Gene 33: $103-119$. 


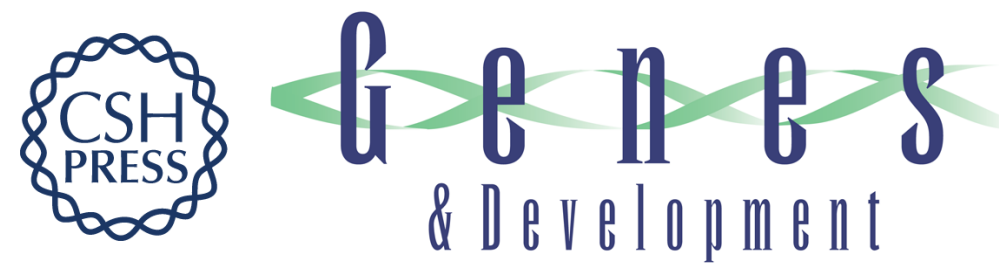

\section{The yeast transcription activator PRTF, a homolog of the mammalian serum response factor, is encoded by the MCM1 gene.}

E E Jarvis, K L Clark and G F Sprague

Genes Dev. 1989, 3:

Access the most recent version at doi:10.1101/gad.3.7.936

References This article cites 33 articles, 11 of which can be accessed free at:

http://genesdev.cshlp.org/content/3/7/936.full.html\#ref-list-1

License

Email Alerting

Service

Receive free email alerts when new articles cite this article - sign up in the box at the top right corner of the article or click here.

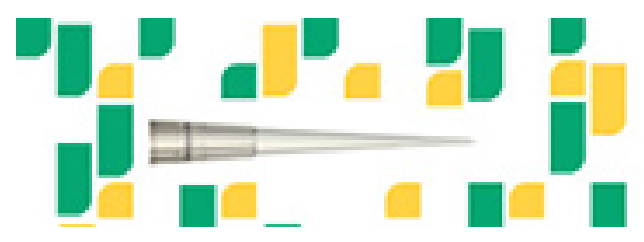

Focused on your science. 